\title{
DE HOLLANDSCHE IJZEREN SPOORWEG-MAATSCHAPPIJ OVER HET JAAR 1874.
}

\author{
(Ingezonden.)
}

De Hollandsche jjzeren spoorweg-maatschappij beeft in 1874 geëxploiteerd : bare eigen spoorweg (Rotterdam-Haarlem-Amsterdam, en Haarlem-Uitgeest, lang 102 kilometers), en het gedeelte van den staatsspoor van Nieuwediep over Uitgeest naar Zaandam (lang 72 kilometers), en te beginnen met $10 \mathrm{Junij}$ bet gedeelte ran den Oosterspoorweg, dio door de genoemde Maatschappij wordt gemaakt van Amsterdam over Hilyersum naar Amersfoort, en van Hilversum naar Utrecht. De lengte van het baanvak Amsterdam-Amersfoort is 45, en van het baanvak Hilversum-Utrecht 18 kilometers.

De opbrengst van het reizigersvervoer op de oude lijn Rotterdam-Amsterdam en Haarlem-Uitgeest bedroeg $f 34.327,07^{5} \mathrm{en}$ op den staatsspoorweg Nieuwediep-Zaandam $f 5800$ meer dan in 1873.

Door de buitengewone stilte in den handel is het goederenvervoer slechts zeer weinig vooruitgegaan, namentlijk met $f 5000$ op den eigen weg en met $f 6000$ op den staatsspoorweg.

De opbrengst van de gedeelten van den spoorweg RolterdamHaarlem-Amsterdam en Haarlem-Uitgeest zijn in de exploitatierekening niet afzonderlijk opgegeven, maar die opbrengst is zamengenomen met die van de Oosterspoorweg; hierdoor is een vergelijking der onderdeelen met 1873 onmogelijk, zoodat wij tot ons leedwezen hier moeten laten volgen de ontvangsten roor den ouden Hollandschen spoorweg en den Oosterspoorweg, be zamen genomen, over 1874.

EcoN. 1875. 


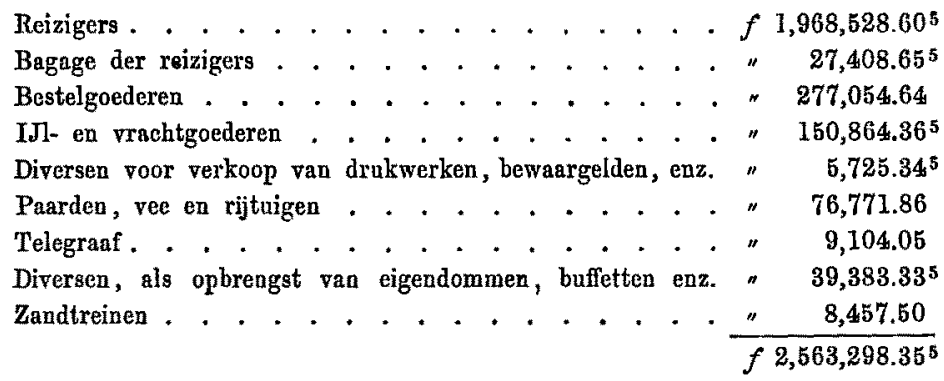

Uit het verslag blijkt, dat de totale opbrengst der oude lijn Rotterdam-Amsterdam, en Haarlem-Uitgeest in 1874 beliep $f 2,263,001.41^{5}$ tegen $f 2,223,544.82^{5}$ in 1873 .

De gemiddelde opbrengat per kilometer per jaar van RotterdamAmsterdan bedroeg $f 24239$ in 1874 , tegen $f 23639$ in 1873 , dus eene vermeerdering $\operatorname{van} f 600$. Deze opbrengst was op het baanvak: Amsterdam-Haarlem $f 28459$; Haarlem-Leiden $f 16813$; Leidenden Haag $f 23061$ en den Haag-Rotterdam $f 31120$.

Het gedeelte Haarlem-Uitgeest (18 k. m.) bragt op $f 9649$ per kilometer in 1874, tegen $f 9563$ in 1873 .

De uitgaven roor den Hollandschen en Oosterspoorweg te zamen beliepen in 1874

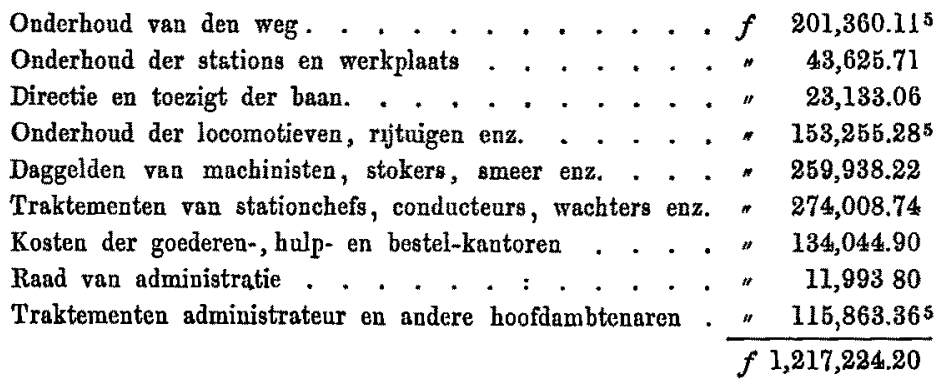

De verhouding tusschen de ontrangston en de exploitatiekosten is in 1874 nog minder gunstig dan in 1873 , en van 45.96 gestegen tot 47.49 percent, een gevolg van de opening van den Oosterspoorweg. De aandeelhouders ontrangen voor ieder aandeel van $f 1000$ over 1874 een dividend van $f 65.90$ tegen $f 68.90$ over 1873.

In ons overzigt over 1873 drukten wij de verwachting uit, dat de reservekas in 1874 zou klimmen tot het maximum in de statuten voorgeschreven, zijnde een millioen gulden. In die verwachting zijn wij te leur gesteld, omdat uit de reservekas de schale moet 
betaald worden voor de ongerallen die in 1874 hebben plaats gehad. De reservekas beliep op 1 Januarij 1874 de som van $f 952,146.35^{5}$, waarbij op het einde van dat jaar aan renten van belegging kwamen $f 46,336.29$, alzoo $f 998,482.644^{5}$; over de dienst van 1874, komt hierbij $f 72,429.90$. Van deze som moet afgetrokken worden de schade door de ongevallen veroorzaakt; reeds is hiervoor betaald $f 59,203.82$, maar alles is nog niet verevend.

De exploitatie van den Noord-Hollandscben Staatsspoorweg gaf aan de Maatschappij geen schoone resultaten, zooals blijkt uit de onderstaande cijfers, zijnde de opbrengst van bet gedeelte Nieuwediep-Uitgeest-Zaandam.

\begin{tabular}{|c|c|c|c|c|}
\hline Reizigers. . & - & & $\begin{array}{c}1873 \\
f 238,335.63^{5}\end{array}$ & $\begin{array}{c}1874 \\
f 244,100.80^{5}\end{array}$ \\
\hline Bagage der reizigers. . & . & . & " $3,091.49^{5}$ & $3,044.14^{5}$ \\
\hline Bestelgoederen . . . . . & . & . & * $19,166.53$ & " $21,772.60^{5}$ \\
\hline Vrachtgoederen. . . . & 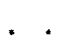 & . & $" 41,568.73^{8}$ & * $44,818.96$ \\
\hline Paarden, ree en rijtuigen. & & . & $9,447.29$ & " $11,18422^{5}$ \\
\hline Laad-, los- en bestelloonen & & . & " $18,668.62^{5}$ & $" 18,918.90^{5}$ \\
\hline Toevallige baten. & & . & $5,589.70$ & $5,860.24$ \\
\hline Telegraaf . . . . . . & $0^{\circ}$ & . & $3,792.98^{5}$ & $4,103.28$ \\
\hline Diverse baten en zandvervoer & & . & $2,653.72$ & $" 6,830.36^{\circ}$ \\
\hline & & & $5,314.71^{5}$ & $f 360,633.52$ \\
\hline
\end{tabular}

De ontrangsten waren dus ongeveer $f 15,000$ hooger, dan in 1873 , waarvan $f 6000$ aan reizigers.

De gemiddelde opbrengst per kilometer bedroeg $f 5079$ in 1874, tegen $f 4863$ in 1873 . Het meest bragt op het baanvak DitgeestAlkmaar, namelijk $f 6653$ en het minst Uitgeest-Zaandam $f 2782$.

Bij eene vergelijking met de opbrengsten van de lijn RotterdamAmaterdam ziet men, dat deze opbrengsten uiterst gering zijn.

De uitgaven beliepen in

\begin{tabular}{|c|c|c|c|c|c|c|c|}
\hline & & & & & & 1873 & 1874 \\
\hline Onderhoud en bewa & king & der & r baan & & - $f$ & $74,047.55$ & $f \quad 71,680.62$ \\
\hline Stationsdienst . . & 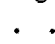 & 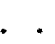 & . . & & . " & $60,222.48$ & $" 63,586.45^{x}$ \\
\hline Tractie . . . & . & . . & . . & . & . & $106,151.40^{5}$ & " $107,962.03^{5}$ \\
\hline Vervoer. . . & $\cdot$ & & & & . & $12,047.80$ & $" 12,292.64$ \\
\hline Onkosten-rekening. & . & . . & & . & • & $14,593.91^{5}$ & $" 16,226.65$ \\
\hline \multirow[t]{2}{*}{ Vernieuwingsfonds } & . & . . & . & . & & $21,056.34$ & " $21,447.73$ \\
\hline & & & & & & 9.49 & $f 293,145.93$ \\
\hline
\end{tabular}

Niettegenstaande de zuivere opbrengst vau den Noord-Holland- 
schen staatsspoorweg in 1874 ongeveer $f 10,000$ booger was, dan in 1873, genoot de Maatsehappij hier niets van, ten gevolge van de onpraktische inrigting van de verdeelingsschaal der concessie. De Staat ontving $f 74,872.65$ over 1874, tegen $f 64,298.53$ over 1873. Volgens de balans werd in 1874 voor de exploitatie van den Noord-Hollandschen spoorweg een som van $f 109,760$ vereiseht.

De exploitatie-kosten waren per kilometer $f 4,129$ in 1874 , tegen $f 4,058$ in 1873 , of met betrekking tot de inkomsten 81.29 tegen 83.44 percent. Laat men nu de intrest der gelden die in de exploitatie gestoken zijn buiten rekening, dan verliest de Maatschappij in 1874 nog $f 7385$ op de exploitatie der lijn Nieuwediep-Zaandam. Vergelijkt men de exploitatiekosten dezer lijn met die van andere lijnen, dan zijn zij zeer hoog.

Den 10den Junij 1874 werd voor het publiek verkeer opengesteld het gedeelte van den Oosterspoorweg van Amsterdam over Hilversum naar Amersfoort en van Hilversum naar Utrecht; het tarief roor vracht- en ijlgoed werd 16 November ingevoerd.

Zoolang de Oosterspoorweg niet minstens tot Zutphen is verlengd en het station te Amsterdam ten gevolge van den tragen voortgang der werken van den Staatsspoorweg en het open havenfront, niel beter voor goederenvervoer kan worden ingerigt, kan over de opbrengst van dit gedeelte van den spoorweg geen just oordeel geveld worden. Zijn wij goed ingelicht, dan werkt reeds nu dit gedeelte van den Oosterspoorweg gunstig voor den bandel van Amsterdam, als concurrent voor den Rijnspoorweg. Men zegt, dat de goederen uit Noord-Duitschland, per Staatsspoorweg te Zutphen aangebragt, van Zutphen over Deventer, Zwolle, Amersfoort en Hilversum buiten den Rijnspoorweg om, naar Amsterdam worden vervoerd; even zoo gaan de goederen uit do Rijnstreken en Zuid-Duitschland over Venlo, Boxtel, 's Hertogenbosch, Utrecht en Hilversum naar Amsterdam.

De opbrengst van den Oosterspoorweg bedroeg $f 300,296.94$; van 10 Junij tot 31 December 1874 was de opbrengst per kilometer tusschen Arasterdam en Amersfoort $f 5259$ en tusschen Hilversum en Utrecht $f 2787$. Toen op de algemeene vergadering van aandeelhouders, gehoudeu den 30sten Maart 1870, de directie van den Hollandscle ijzeren apoorwegmaatschappij voorstelde den. Oosterspoorweg aan te leggen, gaf zij als bare meening te kennen, dat de opbronget per jaar per kilometer zou bedragen roor het 
gedeelte Amsterdam-Utrecht $f 14,000$ en voor HilrersumAmersfoort $f 7,500$. De gemiddelde opbrengst der beide lijnen werd begroot op $f 12,250$ en heeft van 10 Junij tot 31 December bedragen $f 4557$, zijnde een tamelijk goed resultaat. Ongelukkig voor de aandeelhouders zullen de kosten van aanleg van den Oosterspoorweg aanmerkelijk de begrooting overschrijden. De exploitatie van den Oosterspoorweg heeft reeds gevorderd het aanschaffen van twintig locomotieven en ander rollend materieel, een uitgaaf van büna $1_{\frac{1}{2}}$ millioen gulden.

Op de algemeene vergadering van andeelhouders van 30 Mart 1875 is tot ons groot genoegen door de directie roorgesteld en door de vergadering goedgekeurd het maken van een zijlijntje ten eindo het paleis het Loo van Zijne Majeateit den Koning to verbinden met den Oosterspoorweg.

Op genoemde vergadering is wederom ter sprake gebragt de spoorweg Amersfoort-Wageningen-Nijmegen, waarover wij reeds in dit Tijdschrift (zie jaargang 1873, bl. 536) een woord ter aanbeveling hebben geschreven. Deze zaak is meer uitvoerig behandeld in eene brochure getiteld: „De spoorweg AmsterdamAmersfoort-Wageningen-Nijmegen, de kortste verbinding van Amsterdam met den Rijn, door Mr. Jac. Wertheim. Amsterdam bij P. N. van Kampen en Zoon 1875." Wij nemen de vrijheid naar dit belangrijk geschrift te verwijzen, en bopen, dat de onvermoeide pogingen, om dio lijn tot stand to brengen, met een goeden uitslag zullen bekroond worden.

Het jaar 1874 onderscheidde zich van andere jaren door de ongevallen op den spoorweg.

Den 10den Mei viel een remmer-bagayemeester uit den trein tusschen Halfweg en Sloterdijir, en was onmiddelijk dood.

Den 18den Junij kwam een der kinderen van de wachtster aan den Soester-straatweg met de tredo van de machine zoodanig in aanraking, dat er do dood spoedig op volgde.

Den 9denJulij werd to Haarlem een kind bij hel rangeeren van een trein zwaar gekwetet.

Den 11den Julij is te Uitgeest een arbeider bij het af- en aanhalen van wagens tusschen de stootkussens bekneld geraakt en kort daarop overieden.

Den 14den Augustus kwamen bij Warmond twee treinen in bot- 
sing, waardoor zijn gedood een conducteur en een reiziger en gewond twintig reizigers.

Den 25sten Augustus werd een werkman door den verkeerden stand van den wissel te Hilversum ernstig gewond.

Den 3 denOctober doodde een rangeerende goederentrein te Leiden een wisselwachter.

Den 17 den November reed een locomotief zonder trein in de geopende kraanbrug over de Delfsharensehe Schie tussehen Rotterdam en Schiẹdam. Hoewel door dit ongeval niemand persoonlijk gedeerd werd, was de brug zoodanig beschadigd, dat de doorloopende communicatie tusschen de twee stations Rotterdam en Schiedam werd gestremd tot 9 December.

Op bladzijde 536 en 537 van den jaargang 1873 van dit Tijdschrift hebben wij er reeds op gewezen dat het Rijk, ingerolge de concessie, 33 jaar nadat de spoorweg van Amsterdam naar Rotterdam is geopend (dit is geschied 31 Mei 1847) het regt heeft, zich in het bezit van den spoorweg te stellen tegen uitkeering der hoofdsom, dio de tot stand brenging zal gekost hebben, en van zoodanige andere sommen, als met voorkennis en goedvinden der Regering tot verbeteringen als anderzins mogten zijn besteed geworden, en zulks, zonder dat in aanmerking worde genomen, hetgeen de maatschappij of derzelver regtverkrijgende inmiddels aan jaarlijksche renten, dividenden of aflossingen zullen genoten hebben.

$\mathrm{Bij}$ het door velen voorgestane denkbeeld, dat de spoorwegen allen van staatswege moeten geexploiteerd worden, komt het ons wenschelijk - voor, dat de Directie, indien, zooals wij meenen, zulks nog niet is geschied, rot de Regering in overleg trede, om te bepalen, welke sommen tot verbetering als anderzins zijn besteed. Geschiedt dit niet, dan zullen bij eene eventuële naasting de aandeelhouders weinig ontvangen, daar de koopsom voor een goed deel zal moeten dienen tot afbetaling der geldleeningen, docr de Maatschappij aangegaan.

De zucht naar staatsexploitatie is onlangs wederom gebleken bij bet vaststellen der nieuwe wet, tot regeling van de dienst en het gebruik der spoorwegen. Niettegenstaande de vele, o. i. gegronde bezwaren tegen die wet, is zij in de Staten-Generaal met groote meerderheid aangenomen. Wij voor ons, vreezen dat die wet de vrijheid van handelen der spoorwegmaatschappijen zoo zeer zal 
beperken, den invloed van den Staat op den gang ran spoorwegzaken zoodanig zal uitbreiden, dat Staatsexploitatie het onvermijdelijk gevolg zal wezen. Het is ons onbegrijpelijk, dat men van de meerdere magt van den Staat tot inmenging in het spoorwegbeheer goede vruchten verwacht. Men herinnere zich slechts, dat bij geen spoorwegmaatschappij de Regering meer magt heeft dan bij de Maatschappij tot exploitatio van Staatsepoorwegen, en juist over die Maatschappij worden steeds de meeste klagten aangeheven.

In een uitnemende brochure: "Het publiek en de spoorwegmaatschappijen tegenover het wetsontwerp betreffende de spoorwegdiensten door W. B. - Amsterdam 1871," wordt er op gewezen, dat bij het publiek een zekere wrevel tegen de spoorwegondernemingen heerseht, voortspruitende uit onbekendheid met die zaken. De minste onregelmatigheid in den treinenloop, het te laat bezorgen van een pakje, enz. geren aanleiding tot een stortvloed van klagten, even alsof de spoorwegmaatschappijen het publiek opzettelijk wilden teleurstellen. Eene slechts zeer opporvlakkige bekendheid met de vele moeijelijkheden der spoorwegexploitatiën zou een veel christelijker stemming doen ontstaan, en de overtuiging schenken, dat het onmogelijk is door boeten, straffen, voorschriften, reglementen, enz. het publiekte voldoen.
's Hage, 15 April 1875.
J. J. VAY KEREWIJK. 
OVERZIGT van de opbrengst der Middelen (Roofdsom en opcenten) over de zes eerste maanden van 1875, in vergelijking met de raming voor dat jaar, en de opbrengst over hetzelfde tijdvak van 1874 en vorige jaren.

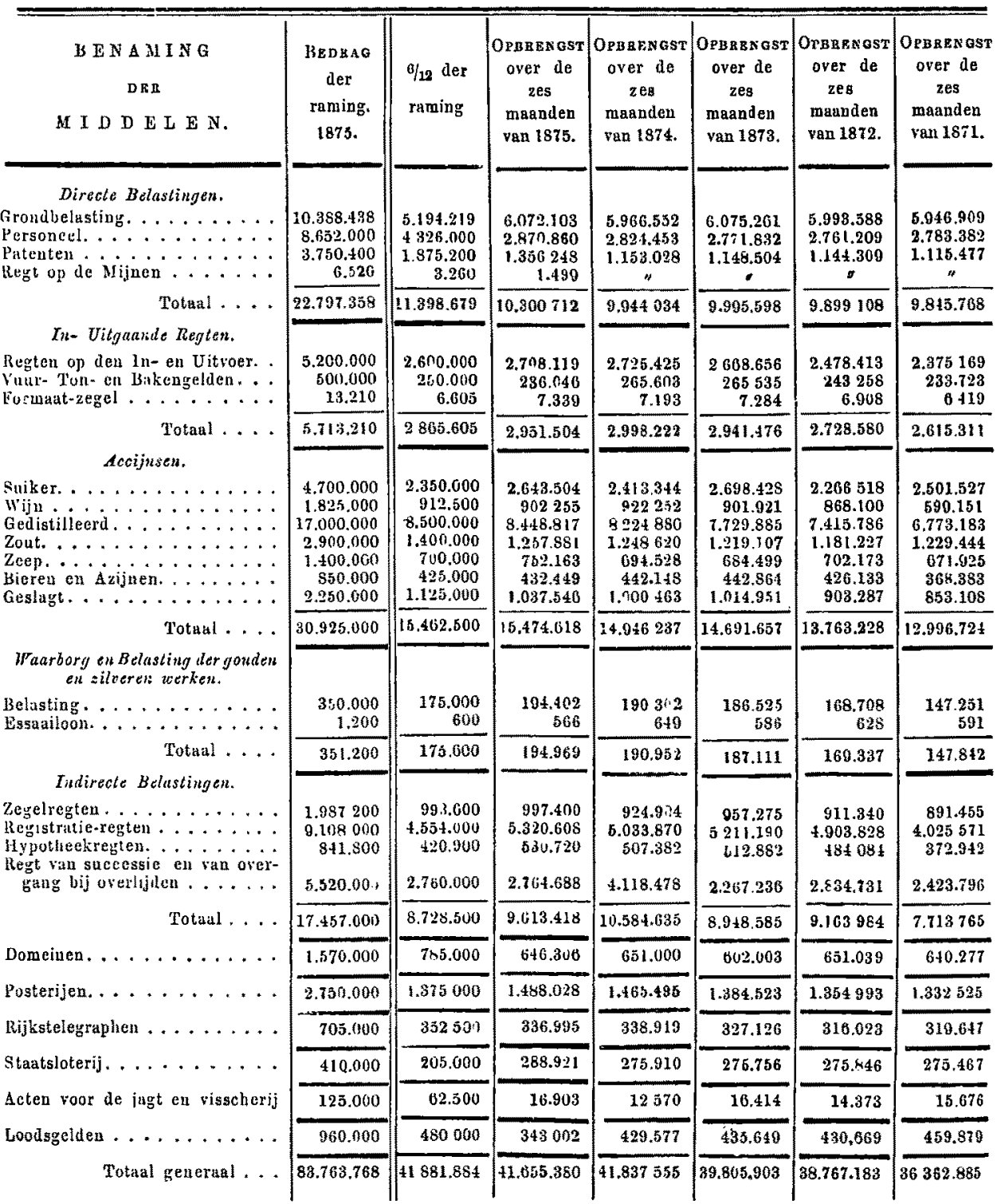

